\title{
Anti-pulling Force and Displacement Deformation Analysis of the Anchor Pulling System of the New Debris Flow Grille Dam
}

\section{Yongsheng WANG ( $\square$ wys5918@lut.edu.cn )}

Lanzhou University of Technology

\section{Baohong LV}

Lanzhou University of Technology

Jianshe Liu

Lanzhou University of Technology

Xiaobin Zhang

Lanzhou University of Technology

\section{Research Article}

Keywords: Debris flow, New grille dam, Anchor-pulling system, Anti-pulling force, Displacement

Posted Date: November 3rd, 2021

DOI: https://doi.org/10.21203/rs.3.rs-1012480/v1

License: (c) This work is licensed under a Creative Commons Attribution 4.0 International License.

Read Full License

Version of Record: A version of this preprint was published at Scientific Reports on March 8th, 2022. See the published version at https://doi.org/10.1038/s41598-022-07722-2. 


\title{
Anti-pulling force and displacement deformation analysis of the anchor
}

\section{pulling system of the new debris flow grille dam}

\author{
Gansu 730050, China. \\ *Corresponding Author.wys5918@lut.edu.cn \\ these authors contributed equally to this work
}

Yongsheng WANG ${ }^{1,2 *}$ Baohong LV ${ }^{1,2,+}$ Jianshe Liu ${ }^{1,2,+}$ Xiaobin Zhang ${ }^{1,2,+}$

1 School of Civil Engineering, Lanzhou University of Technology, Lanzhou 730050, China;

2 Key Laboratory of Disaster Prevention and Mitigation in Civil Engineering of Gansu Province, Lanzhou University of Technology, Lanzhou,

Abstract: To avoid waste from a large section space structure layout and deep burial to improve the structural strength and stability, anchor technology is introduced, and combined with the advantages of the supporting wall, a new debris flow grille dam is proposed. Starting from the force process and damage mechanism of the new debris flow grille dam, the computation formula for the anti-pulling force and the total displacement is given. The anti-pulling force includes the sidewall frictional resistance of the anchor pier and the positive pressure of the front end face of the anchor pier. The total displacement includes three parts: the elastic deformation of the cable, the relative shear displacement between the anchor pier and the surrounding soil, and the compression deformation of the soil at the front of the anchor pier. Finally, the influence of soil parameters and anchor pier size on the anti-pulling force and displacement deformation of the anchor-pulling system is analyzed by examples, and the results are compared with the numerical results. The results show that the displacement deformation decreases gradually with increasing elastic modulus of the soil around the anchor pier and increases with increasing Poisson's ratio. The change in elastic modulus mainly affects the relative shear displacement of the anchor pier and soil and the compressive deformation of the soil at the front end of the anchor pier. Poisson's ratio has the greatest influence on the relative shear displacement of the anchor pier and soil. A larger anchor pier is not better; thus, it is wise to choose the economic design dimension. Theoretical and numerical simulation results are consistent, showing a linear growth trend. The results of this paper can further improve the theoretical calculation method of the new debris flow grille dam, thus making it widely used in more debris flow control projects.

Keywords: Debris flow, New grille dam, Anchor-pulling system, Anti-pulling force, Displacement

\section{Introduction}

The anchoring technique or anchor method, the general designation of design and construction technology, refers to the skill that one end of the tension member is fixed to the rock and soil body and the other is linked with engineering structures to withstand the thrust or the uplift force caused by the earth pressure, water pressure or other external force applied to the structure so that the internal resistance of rock and soil body can be utilized ${ }^{1}$. Commonly used anchorages in engineering include rods using rigid members as pull rods and anchor cables using flexible members as pull rods, which are collectively called ${ }^{\text {anchors2-3. }}$

The earliest use of anchoring technology can be traced back to the 19th century. In 1872, the anchor reinforcement slope was first used in open shale mines in North Wales in British; in 1912, the bolt support underground mine roadway was first used in the Seleznev mine in Germany; in 1915-1920, bolt support technology was gradually used in metal mines in the US; before 1924, anchor spray support was used in the Donbass mine in the Soviet Union ${ }^{4-5}$. In China, over the past decade, the rock-soil anchoring technique has thrived in the field of rock 
and soil reinforcement because of its unique effect, simple process, wide range of uses and economic cost. Anchoring technology has touched almost every corner of the field of civil engineering, such as mine shafts, railway tunnels, underground chamber supports, geotechnical slope reinforcement, foundation stability, deep foundation pit support, anti-floating and anti-overturning structures, underground tensile structures of suspension-cable buildings, construction, reconstruction and expansion of concrete structures. The progress of anchoring technology will effectively promote the development of civil engineering industries and promises a very broad application ${ }^{6-7}$.

Ground anchors, as an anchoring technique, are widely used in the construction of towers and cables ${ }^{8}$. It is also commonly used to anchor and tract the wire rope, brake the wire rope, winch, cable and other load-carrying equipment, and pass an external force to the foundation. Ground anchors are an important load-carrying part that is directly related to the safety of tower construction, economy and rationality ${ }^{9-10}$. The effect of ground anchoring mainly depends on the interaction of soil and ground anchors, and its mechanical mechanism of load transfer is often caused by a potential displacement of the anchor or soil ${ }^{11}$. Accordingly, ground anchors can be divided into two types: active and passive. Active ground anchors, which load onto the anchor initiatively, keep the soil relatively motionless. Therefore, the interaction of anchors and soil is caused by the stretching and displacement of the anchor. The anchor used to support the superstructure load is one particular instance, and the pull-out test is the same. On the other hand, passive ground anchors, which anchor into the soil, constrain the potential displacement of the soil. Therefore, the interaction of anchors and soil is mainly caused by soil displacement. Tunnel support structures, retaining walls and soil displacement control of slope stability are examples of such applications of anchors 12 .

In the prevention and control engineering of debris flow, to resist the impact of debris flow fluid and large stones, a large section of structural member is often designed to enhance the lateral stiffness of grille dam, deep-bury about half the length of the pile and arrangement forms of spatial structure are designed to guarantee the stability of the grille dam ${ }^{13-15}$. This design concept is feasible for a single dam when a large-scale debris flow occurs but is very wasteful for medium- and small-scale debris flow ${ }^{16}$ and integrated control of the entire river basin ${ }^{17-20}$. While the new debris flow grille-dam structure the authors proposes, which is the first try to introduce ground anchor technology to the control structures of debris flow, ingeniously combines the advantages of ground anchors and buttresses so that both the rigidity of dam and the reliable stability can be ensured ${ }^{21}$.

To improve the theoretical calculation method of the new debris flow grille-dam structure and make it widely used in more areas and fields, the paper starts from the loading process and failure mechanism of the new debris flow grille-dam system and then analyzes the anti-pulling force and displacement deformation of the anchor-pulling 
system. The anti-pulling force mainly consists of the frictional resistance of the lateral walls of the anchor piers and the positive pressure on the front of them; the total displacement is comprised of the elastic deformation of the stayed cable, the relative shear displacement caused by the anchor pier and surrounding soil and the compression deformation of the soil in front of the anchor pier. Finally, the author tests and verifies the correctness of the calculation model through numerical simulation and analyses the influence of the thickness of the overlying soil, the shapes of the anchor pier and other factors on the anti-pulling force and displacement deformation of the anchorpulling system.

\section{The New Debris Flow Grille-dam}

\subsection{Introduction of the new debris flow Grille-dam}

The new debris flow grille dam is mainly composed of grilles, which consist of columns, beams and waste profiled bar beams, foundation piles, counterfort walls, stayed cables, anchor piers, bottom plates and bottom beams. As shown in Figure 1. The use of the grille structure of reinforced concrete grille columns and grille beams embedded with profiled bar beams has realized the aim of the combination of retaining and draining for debris flow. Moreover, the stayed cable of the ground anchor can guarantee the integral stability of this new grille dam. In addition, the reinforced concrete counterfort walls play a role in protecting the stayed cable from being broken and in splitting the flow, which makes the stress on the grille dam relatively even.

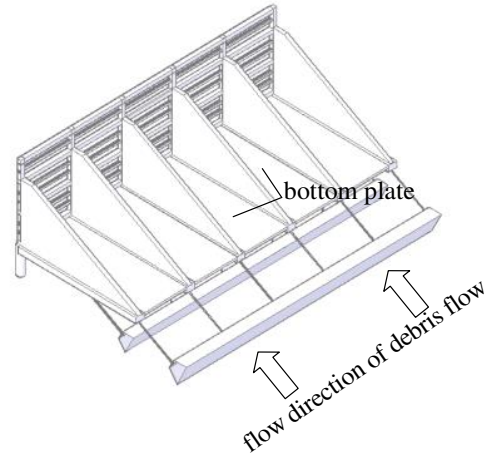

(a) Oblique View

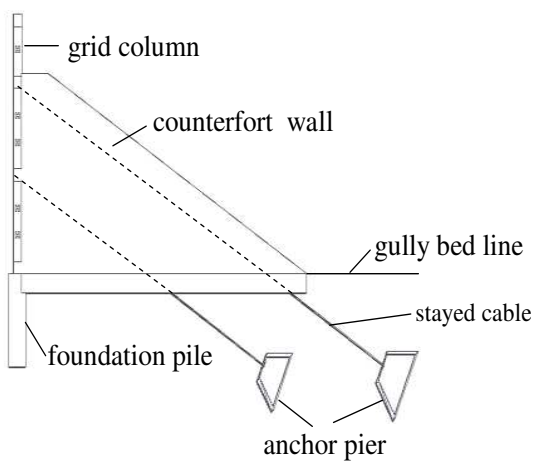

(b) Side Elevation View

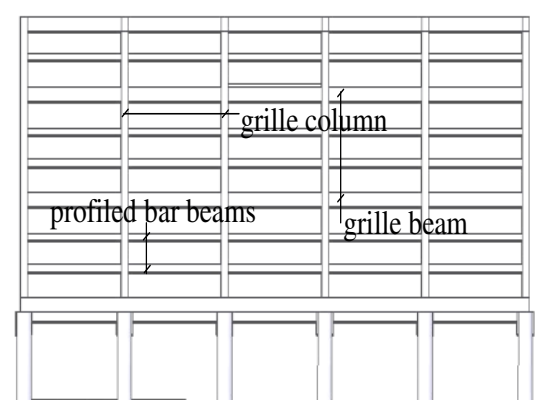

(c) Front Elevation View

Fig. 1. The Structure for the Grille-dam.

\subsection{Features}

As a kind of permeable structure for debris flow control that has strong stability, good permeability of water and less material consumption, its main features are: leaving the larger gravel behind and releasing the solid particles which are less harmful to the downstream in order to achieve the combination of retaining and draining; controlling the diameter of the releasing solid particles by adjusting the spacing of the grille; keeping the fluvial equilibrium by adjusting the proportion and composition of retaining and draining; improving the structure's service life by adjusting 
the gate hole to make the fine-grained materials in the pool washed away by using the running water after rainy season; draining water rapidly to reduce water pressure and uplift pressure the structure withstanding and to improve the stability of the structure; conducive to prefabricated and light development, saving material and shortening construction period.

\subsection{Scope of Application}

According to the experience of disaster site research and the success or failure of existing control structure ${ }^{22}$, the new debris flow grille dam is mainly suitable for controlling middle- and small-scale debris flows. It is also suitable if there are fewer large stones and large floating rocks in the material source or if the channel fall is relatively low and flat. It can be used as a single structure in controlling debris flows or combined with other structures in the comprehensive control of the whole basin.

\section{Calculation Model of the Anti-pulling Force for the Anchor-Pulling System}

\subsection{The failure mechanism of anchor-pulling system}

\subsubsection{Mechanical composition}

When the new grille dam is under the pressure of debris flow, pressure of debris flow deposit, hydrodynamic pressure and impact force of crossing the dam debris flows, the force on the dam body is transmitted to the stayed cable through the grille columns and beam nodes and then to the anchor piers in the deep stable region, eventually realizing the requirements of the safety and stability of the dam body and putting the structure under reasonable load. The anti-pulling force of the anchor-pulling system is comprised of two parts, including the frictional resistance between the lateral walls of the anchor piers and the soil body as well as the positive pressure on the front of the anchor piers, which belongs to the frictional-end pressure anchor-pulling system.

\subsubsection{Failure modes}

The failure of the anchor-pulling system mainly takes three forms: the failure of the stayed cable, the failure of the connection with anchor heads and anchor piers, and the failure of the soil body around the anchor piers.

The failure of the stayed cable: the anchor piers deeply buried in the stable region can provide a huge anchoring force, so the strength of the stayed cable becomes a weak link that the steel strand may be fractured and reinforcement yielding may occur under the great impact of debris flows.

The failure of connections with anchor heads and anchor piers: theoretically, when the strength of the stayed cable is great enough, the connections between the stayed cable and anchor heads related to the grille beam nodes or the connections between the stayed cable and anchor piers become the weakest link. If there are construction quality 
problems on the joint or the connection is impacted by large stones in the debris flows, the stayed cable will be pulled out of anchor piers or grille beam nodes, resulting in the failure of connections.

The failure of the soil body around the anchor piers: When the strength of the stayed cable is great enough and the connections between the stayed cable and anchor piers or grille beam nodes are reliable enough, the failure of the soil body around the anchor piers will take place.

Among the three forms mentioned above, the first two forms can easily be prevented by selecting reasonable structural material parameters and setting a variety of structural measures. This paper only discusses the third failure of the soil body around anchor piers. Now, we take an equivalent anchor-pulling system as the object to discuss. The failure of the soil body around the anchor piers may be classified into 4 phases.

The first phase: The phase of earth pressure at rest. As shown in Figure 2, when the external load on the stayed cable is relatively small, the lateral walls of the anchor piers bear frictional resistance, while the front of them bear earth pressure at rest. In this phase, the displacement of the anchor-pulling system is small, and the force-deformation properties of the system are determined by the distortion of the stayed cable.

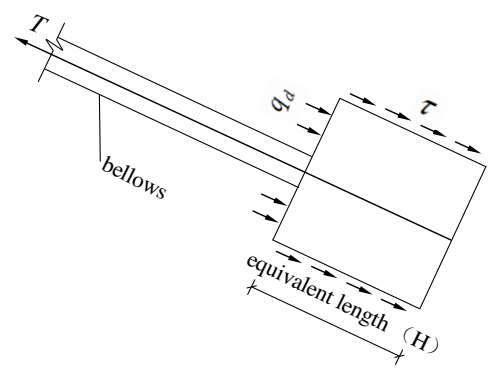

Fig. 2. The Force Diagram of the Anchor-pulling System in the Phase of Earth Pressure at Rest.

The second phase: The phase of transition. After the frictional resistance of the lateral walls of the anchor piers peaked, if the external tension on the stayed cable continued to grow, the anchor piers began to move forward, the pressure on the front of them increased, and the soil body in the front began to produce a local plastic zone, as shown in Figure 3. If the external tension on the stayed cable continues to grow, the plastic zones of the soil body will expand and finally be jointed to form a whole, as shown in Figure 4. Before this phase, the force-deformation properties of the system are determined by the frictional resistance of the anchor piers. Afterwards, it is determined by the compression performance of the soil on the front of anchor piers. As the compression deformation of the soil is greater than the frictional deformation, one of the significant features is that an inflection point appears on the tension-displacement curve. After it, the slope of the curve decreases, and the displacement increases. This inflection point can be referred to as "the end pressure inflection point". 


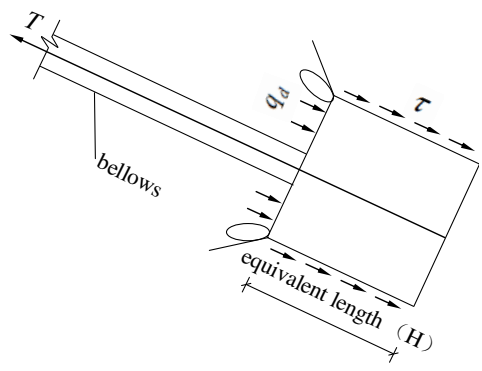

Fig. 3. Force Diagram of the Anchor-pulling System in the Phase of Transition (Emergence of plastic zone).

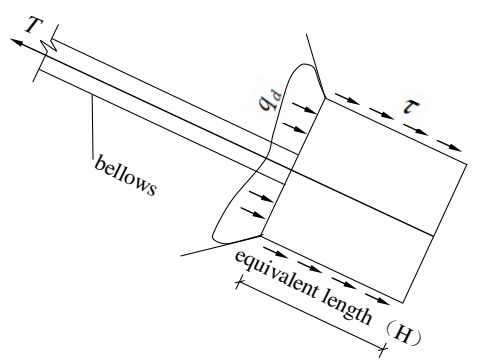

Fig. 4. Force Diagram of the Anchor-pulling System in the Phase of transition (Joint of plastic zone).

The third phase: The phase of compaction-expansion in the plastic zone. After the end pressure inflection point, if the external tension on the stayed cable keeps growing, the anchor piers will have large displacement forward, and under the constraint of confining pressure of the surrounding soil along with the pressure of anchor piers, compression and stress redistribution of the soil body in the plastic zone will occur, as shown in Figure 5. When the embedded depth of anchor piers is relatively large, as the external tension on the stayed cable grows, the soil is constantly pressed so that the resisting force of anchor piers provided by the pressed soil increases and the displacement of the anchor-pulling system tends to be stable, as shown in Figure 6.

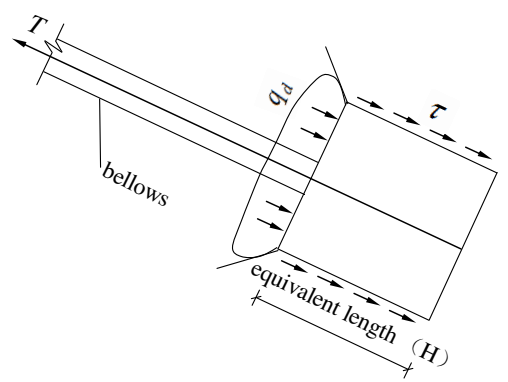

Fig. 5. Force Diagram of the Anchor-pulling System in the Phase of Compaction-Expansion in the Plastic Zone (Expansion of plastic zone).

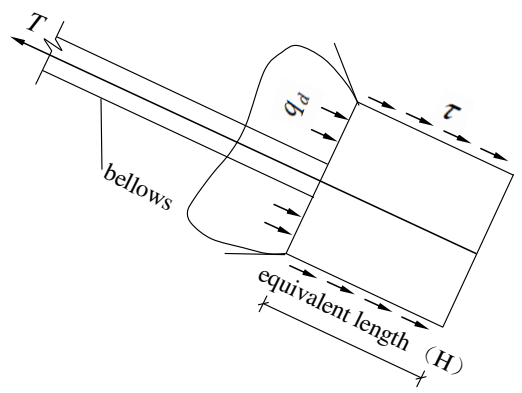

Fig. 6. Force Diagram of the Anchor-pulling System in the Phase of Compaction-Expansion in the Plastic Zone (Stability of compaction). 
The fourth phase: The phase of the anchor piers being pulled out. When the compaction in the plastic zone of the soil on the front of the anchor piers is stable, with the further increase in the external tension on the stayed cable, the deadweight of the overlying soil of the anchor piers cannot balance the oblique pulling force of the stayed cable and finally tends toward the limiting equilibrium condition. If the tension of the external load on the stayed cable increases to be large enough, the soil on the front of the anchor piers will form a "funnel-shaped" failure surface, and the anchor piers with the surrounding soil will be pulled out, as shown in Figure 7.

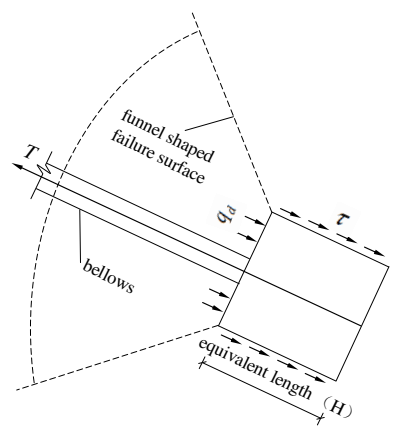

Fig. 7. The Force Diagram of the Anchor-pulling System in the Phase of the Anchor Piers Being Pulled out.

3.2 Calculation model of the anti-pulling force for the anchor-pulling system

Considering the third form of failure above, the mechanical model is shown in Figure 8 and Figure 9. For the convenience of formula derivation and engineering applications, the trapezoid anchor piers in Figure 8 can be replaced by the equivalent rectangular anchor piers in Figure 9.

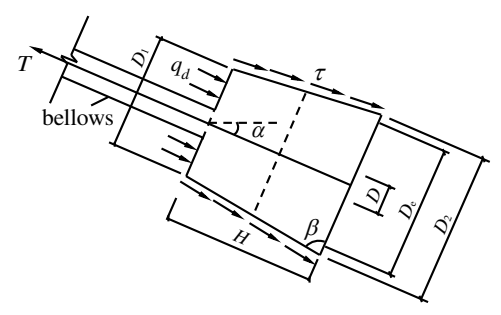

Fig. 8. The Mechanical Model of Trapezoid Anchor Piers.

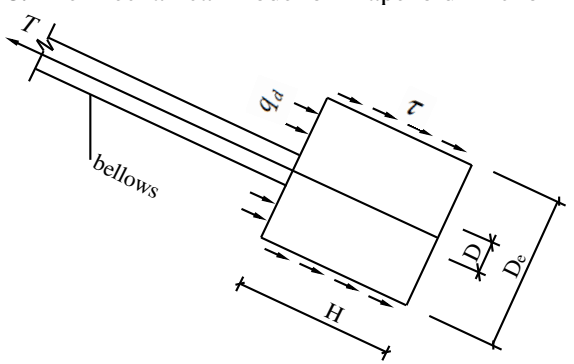

Fig. 9. The Mechanical Model of Equivalent Rectangular Anchor Piers.

The anti-pulling force of the anchor-pulling system $T_{b}$ is composed of two parts: the anti-pulling force provided by the frictional resistance of the lateral walls $T_{1}$ and the soil positive pressure on the front of the anchor piers $T_{2}$.

That is:

$$
T_{b}=T_{1}+T_{2}
$$


where $T_{1}$ is the anti-pulling force provided by the frictional resistance of the lateral walls and can be calculated using the following equation:

$$
T_{1}=2\left(D_{e}+L_{m}\right) \cdot H \cdot \tau
$$

$T_{2}$ is the soil positive pressure on the front of the anchor piers and can be calculated using the following equation:

$$
T_{2}=\left(D_{e} L_{m}+\frac{\pi}{4} D^{2}\right) q_{d}
$$

Here, $D_{e}$ is the section width of the equivalent anchor piers, $D_{e}=\left(D_{1}+D_{2}\right) / 2 ; L_{m}$ is the section length of the equivalent anchor piers; $H$ is the section height of the equivalent anchor piers; $\tau$ is the intensity of frictional resistance between the lateral walls of the anchor piers and the formation ${ }^{23} ; D$ is the diameter of the corrugated sleeve of the protective stayed cable; and $q_{d}$ is the intensity of the soil's positive pressure on the front of the anchor piers.

\section{Calculation Model of Deformation for Anchor-Pulling System}

When the new Grille dam is under the pressure of debris flow, earth pressure of debris flow deposit, hydrodynamic pressure and impact force of crossing the dam debris flows, the force on the dam body is transmitted to the anchor-pulling system in the deep stable region through the grille columns and beam nodes. In the whole loading process, if the pulling force of the stayed cable is greater than its ultimate tensile strength, the frictional resistance of the lateral walls is greater than the soil ultimate shearing strength, the plastic zones form a whole when the soil on the front of the anchor piers is compressed, and failure of the anchor-pulling system will occur. Therefore, the total displacement of the system $S$ can be expressed using elastic deformation of the stayed cable $S_{1}$, relative shear displacement between anchor piers and the surrounding soil $S_{2}$ and the compression performance of the soil on the front of anchor piers $S_{3}$, that is, $S=S_{1}+S_{2}+S_{3}$.

4.1 Analysis of elastic deformation of the stayed cable

As the pulling force of the stayed cable is the external load transmitted by the grille columns and beam nodes, according to Hooke's law, we know that:

$$
S_{1}=\frac{T L_{l}}{E_{l} A_{l}}
$$

where $L_{l}$ is the length of the stayed cable; $T$ is the pulling force that the stayed cable bears; $E_{l}$ is the elastic modulus of the stayed cable; and $A_{l}$ is the sectional area of the stayed cable.

4.2 Analysis of the relative shear displacement between anchor piers and the surrounding soil

To analyze the relative shear displacement between equivalent anchor piers and the surrounding soil, we take 
anchor piers as free bodies and take one of them as a unit body. Its force is shown in Figure 10.

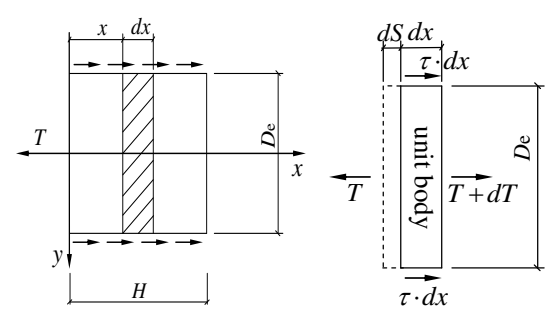

Fig. 10. Analytical diagram of the load transfer of the anchor piers.

From the static equilibrium of the unit body, there exists:

$$
\frac{\partial \sigma}{\partial x}=-\frac{2\left(L_{m}+D_{e}\right) \tau}{A_{e}}
$$

where $\sigma$ is the section mean normal stress of the equivalent anchor piers, $\sigma=T / A_{e} ; \tau$ is the intensity of frictional resistance between the lateral walls of the anchor piers and the formation; $A_{e}$ is the section area of the equivalent anchor piers, $A_{e}=d_{e} L_{m}$; and $D_{e}$ is the section width of the equivalent anchor piers.

So axial strain of unit body turns to:

$$
\varepsilon=\frac{\partial S}{\partial x}=-\frac{\sigma}{E_{e}}=-\frac{T}{D_{e} L_{m} E_{e}}
$$

where $S$ is the displacement of the unit body; $L_{m}$ is the section length of the equivalent anchor piers; and $E_{e}$ is the elastic modulus of the equivalent anchor piers.

If we assume that there is a linear elastic incremental relationship ${ }^{24}$ between the shear force and shear displacement of the soil around the anchor piers, then

$$
2\left(L_{m}+D_{e}\right) \tau=G_{S} S
$$

where $G_{S}$ is the shear modulus between the anchor piers and soil interfaces, the physical meaning of which is the shear force produced by unit shear displacement on the unit section length of the equivalent anchor piers. After differentiating equation (6) and solving simultaneous equations (5) and (7), we can obtain the second-order differential equation of load transfer of the anchor piers

$$
\frac{\partial^{2} S}{\partial x^{2}}-\frac{G_{S} S}{D_{e} L_{m} E_{e}}=0
$$

Let $G_{s} a=\sqrt{G_{s} / D_{e} L_{m} E_{e}}$, the general solution of the equation above is:

$$
S(x)=C_{1} \exp (a x)+C_{2} \exp (-a x)
$$

Substituting the boundary conditions and $\left(\frac{\partial S}{\partial x}\right)_{x=0}=-\frac{T}{D_{e} L_{m} E_{e}},\left(\frac{\partial S}{\partial x}\right)_{H=0}=0$ the relative shear displacement of the anchor piers is obtained. 


$$
S(x)=\frac{T[\exp (a)+\exp (2 a H-a x)]}{a D_{e} L_{m} E_{e}[\exp (2 a H)-1]}
$$

Substituting $x=0$ and $x=H$ into the equation above, we can obtain the relative shear displacement of the top and bottom of the anchor piers:

$$
\begin{aligned}
& S(0)=\frac{T}{a D_{e} L_{m} E_{e}} \cdot \frac{\exp (2 a H)+1}{\exp (2 a H)-1} \\
& S(H)=\frac{T}{a D_{e} L_{m} E_{e}} \cdot \frac{2 \exp (a H)}{\exp (2 a H)-1}
\end{aligned}
$$

According to the continuity of the soil, we know that $S(H)$ is the relative shear displacement between the anchor piers and the surrounding soil $S_{2}$, that is, $S(H)=S_{2}$.

4.3 Calculation of the compression performance of the soil on the front of anchor piers based on semi-infinite body theory

When the anchor piers are deeply buried in the stable region, we can assume that the force of the soil around its front satisfies the condition for the distributed pressure in the finite area on a semi-infinite boundary plane. The lengths of the equivalent rectangle are $D_{e}$ and $L_{m}$, and there is uniform pressure with a degree of 1 on this equivalent area.

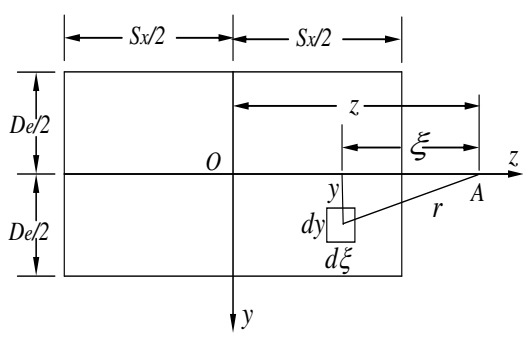

Fig. 11. Analytical diagram of the compression area of the anchor piers.

In Figure 11, the equivalent rectangle represents the range of loading. Now, we will solve the settlement $S_{k i}$ of a point $A$ on the symmetry axis of the equivalent rectangle, the distance of which to the center of the rectangle $\mathrm{O}$ is $z$. Therefore, this uniform unit force can be divided into several microconcentrated forces. Then, the contribution that every microconcentrated force makes to the settlement of point A and the effect of all the microconcentrated forces in the range of loading are determined. Finally, we obtain the actual settlement of point A at this time. Let $d P=1 /\left(D_{e} L_{m}\right) d \varepsilon d y$; the settlement of a point caused by this microconcentrated force can be calculated by equation ${ }^{1225}$, that is,

$$
d S_{k i}=\frac{1-\mu^{2}}{\pi E} \cdot \frac{1}{D_{e} L_{m}} d \varepsilon d y \cdot \frac{1}{r}=\frac{1-\mu^{2}}{\pi E} \cdot \frac{1}{D_{e} L_{m}} \cdot \frac{1}{\sqrt{\varepsilon^{2}+y^{2}}} d \varepsilon d y
$$


Now, we only have to integrate $\varepsilon$ and $y$ on the whole loading plane to obtain the final settlement $S_{k i}$ of point

$A$. Here, $r=\sqrt{\varepsilon^{2}+y^{2}}$.

$$
S_{k i}=\frac{1-\mu^{2}}{\pi E} \int_{Z-S_{x} / 2}^{Z+S_{x} / 2} \int_{-D_{e} / 2}^{D_{e} / 2} \frac{1}{\sqrt{\varepsilon^{2}+y^{2}}} \frac{1}{D_{e} L_{m}} d \varepsilon d y=\frac{1-\mu^{2}}{\pi E L_{m}} K_{k i}
$$

where:

$$
\begin{aligned}
K_{k i}= & \left(\frac{2 \frac{Z}{L_{m}}+1}{\frac{D_{e}}{L_{m}}} s h^{-1} \frac{\frac{D_{e}}{L_{m}}}{2 \frac{Z}{L_{m}}+1}+s h^{-1} \frac{2 \frac{Z}{L_{m}}+1}{\frac{D_{e}}{L_{m}}}\right) \\
& -\left(\frac{2 \frac{Z}{L_{m}}-1}{\frac{D_{e}}{L_{m}}} s^{-1} \frac{\frac{D_{e}}{L_{m}}}{2 \frac{Z}{L_{m}}-1}+s h^{-1} \frac{2 \frac{Z}{L_{m}}-1}{\frac{D_{e}}{L_{m}}}\right)
\end{aligned}
$$

If point $A$ is at the center point $O$ of the equivalent rectangle and $z=0$, which is the location point of the stayed cable, the settlement is:

$$
\begin{aligned}
S_{k i} & =\frac{1-\mu^{2}}{\pi E} \int_{-S_{x} / 2}^{S_{x} / 2} \int_{-D_{e} / 2}^{D_{e} / 2} \frac{1}{\sqrt{\varepsilon^{2}+y^{2}}} \frac{1}{D_{e} L_{m}} d \varepsilon d y \\
& =\frac{1-\mu^{2}}{\pi E L_{m}} \cdot\left(\frac{L_{m}}{D_{e}} \operatorname{sh}^{-1} \frac{D_{e}}{L_{m}}+\operatorname{sh}^{-1} \frac{L_{m}}{D_{e}}\right)
\end{aligned}
$$

After determining the settlement $S_{k i}$ of the center point of the equivalent rectangle under uniform unit pressure, we can obtain the compression performance of the soil on the front of anchor piers $S_{3}$ under the action of tension $T$, that is:

$$
S_{3}=T S_{k i}=\frac{T\left(1-\mu^{2}\right)}{\pi E L_{m}} \cdot\left(\frac{L_{m}}{D_{e}} s h^{-1} \frac{D_{e}}{L_{m}}+s h^{-1} \frac{L_{m}}{D_{e}}\right)
$$

From the above analysis, the total displacement of the system is

$$
\begin{gathered}
S=S_{1}+S_{1}+S_{1} \\
=\frac{T L_{1}}{E_{l} A_{l}}+\frac{T}{a D_{e} L_{m} E_{e}} \cdot \frac{2 \exp (a H)}{\exp (2 a H)-1}+ \\
\frac{1-\mu^{2}}{\pi E L_{m}} \cdot\left(\frac{L_{m}}{D_{e}} \operatorname{sh}^{-1} \frac{D_{e}}{L_{m}}+s h^{-1} \frac{L_{m}}{D_{e}}\right)
\end{gathered}
$$

\section{Analysis of Examples}


The main design parameters of the new Grille-dam are: concrete grade-C30, the stressed steel bars of grille columns and beams-HRB335, stirrups-HPB300, the stayed cables-seven steel strands $3 \phi s 15.2$, each standard value of ultimate strength is $1860 \mathrm{~N} / \mathrm{mm}^{2}$, area of section is $140 \mathrm{~mm} 2$; the height of Grille-dam is $8 \mathrm{~m}$, column section is 500 $\mathrm{mm} \times 700 \mathrm{~mm}$, the space between them is $5000 \mathrm{~mm}$; beam section is $400 \mathrm{~mm} \times 300 \mathrm{~mm}$, the space between them 4000 $\mathrm{mm}$; Steel beams-joist steel $45 \mathrm{a}$, the space between them is $250 \mathrm{~mm}$; The thickness of buttress wall is $300 \mathrm{~mm}$, the height of it is $6500 \mathrm{~mm}$, the thickness of bottom plate is $200 \mathrm{~mm}$; The artificial pore-forming pouring pile is used for pile foundation, Pile diameter is $1000 \mathrm{~mm}$, depth is $5000 \mathrm{~mm}$. The design size of the anchor piers is shown in Figure $12, T=2 \times 10^{5} \mathrm{~N} ; L_{l}=8500 \mathrm{~mm} ; E_{l}=1.95 \times 10^{5} \mathrm{~N} / \mathrm{mm}^{2} ; A_{l}=420 \mathrm{~mm} ; D_{e}=1000 \mathrm{~mm} ; L_{m}=1200 \mathrm{~mm} ;$ $E_{e}=3.0 \times 10^{4} \mathrm{~N} / \mathrm{mm}^{2} ; H=1000 \mathrm{~mm} ; \mu=0.2 ; E=20 \mathrm{~N} / \mathrm{mm}^{2}$. The parameter of gully bed soil is shown in Table 1.
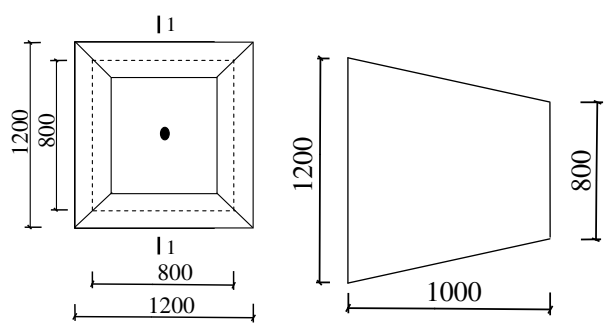

a) Planar graph of anchor piers

Fig. 12. The parameters of anchor piers.

b) Profile 1-1

\begin{tabular}{|c|c|c|c|c|}
\hline $\begin{array}{l}\text { Elastic modulus } \\
(\mathrm{MPa})\end{array}$ & Poisson's ratio & $\begin{array}{c}\text { Cohesive strength } \\
(\mathrm{kPa})\end{array}$ & $\begin{array}{l}\text { Internal Friction angle } \\
\qquad\left(^{\circ}\right)\end{array}$ & $\begin{array}{l}\text { unit weight } \\
\qquad\left(\mathrm{kN} / \mathrm{m}^{3}\right)\end{array}$ \\
\hline 20 & 0.2 & 8.0 & 35.0 & 21 \\
\hline
\end{tabular}

Table 1 The parameters of gully bed soil.5.2 Analysis of Results.

(1) The effect of the elastic modulus and Poisson's ratio of the surrounding soil on the displacement deformation of the anchor-pulling system

The elastic modulus $E$ and Poisson's ratio $\mu$ are important parameters for calculating the displacement deformation of soil. They have something to do with both the properties of materials and the stress level. To analyze the effect of the physical parameter variation of the surrounding soil on the displacement deformation of the anchorpulling system, we can study changing the elastic modulus and Poisson's ratio. The variation range of the elastic modulus is $15 \sim 45 \mathrm{~N} / \mathrm{mm}^{2}$, and the variation range of Poisson's ratio is $0.15 \sim 0.25$. 


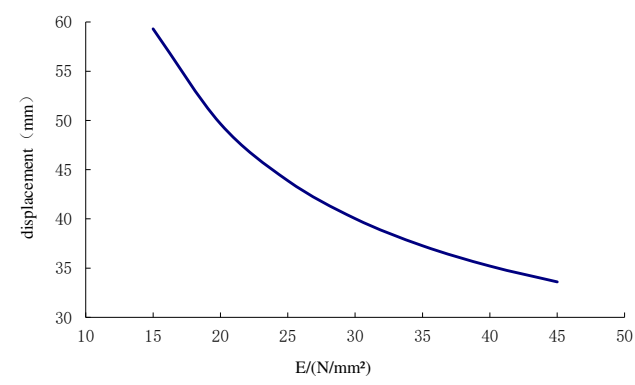

Fig. 13. The effect of the elastic modulus of the surrounding soil on the displacement of the anchor-pulling system.

Figure 13 shows the variation curve in which the displacement deformation increases with the elastic modulus of the soil around the anchor pier. We can see that as the elastic modulus of the soil around the anchor pier increases, the displacement deformation decreases gradually. When the elastic modulus is in the range of $15 \sim 35 \mathrm{~N} / \mathrm{mm}^{2}$, the curve is steep, and the decrease in deformation is apparent. After $35 \mathrm{~N} / \mathrm{mm}^{2}$, the curve becomes smooth, and the decrease in deformation tends to be stable.

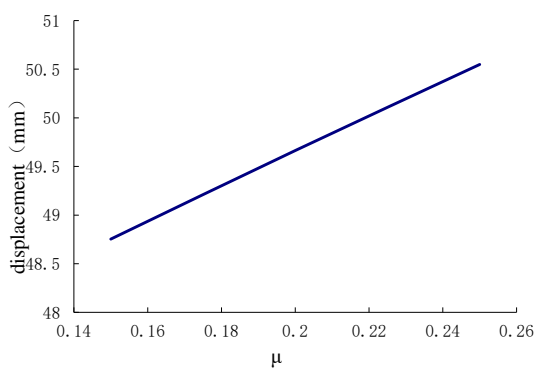

Fig. 14. The effect of Poisson's ratio of the surrounding soil on the displacement of the anchor-pulling system

In Figure 14, the displacement deformation increases linearly with Poisson's ratio of the soil around the anchor pier, but the total impact is not large. From calculation, the variation of elastic modulus of the soil around the anchor pier has nothing to do with elastic deformation of the stayed cable $S_{1}$, but mainly influences relative shear displacement between anchor piers and the surrounding soil $S_{2}$ and the compression performance of the soil on the front of anchor piers $S_{3}$. where $S_{2}$ accounted for $89 \%$ and $S_{3}$ accounted for $11 \%$. When the Poisson ratio increases, the displacement deformation also increases. Poisson's ratio has the greatest influence on the relative shear displacement $S_{2}$ of the anchor pier and soil, accounting for approximately $96.4 \%$. The design parameters should be selected correctly during design.

(2) The effect of the design parameters of anchor piers on the displacement deformation of the anchor-pulling system The design parameters of anchor piers include the equivalent width $D_{e}$, length $L_{m}$ and height $H$. Different design parameters have varying effects on the displacement deformation of the anchor-pulling system. Keep other parameters unchanged and let $D_{e}$ vary in $0.5 \sim 1.5 \mathrm{~m}, L_{m}$ vary in $0.6 \sim 2.0 \mathrm{~m}$, and $H$ vary in $0.5 \sim 1.5 \mathrm{~m}$. Analyzing their effect on the displacement deformation of the anchor-pulling system, the results are shown in Figure 15 and Figure 16. 


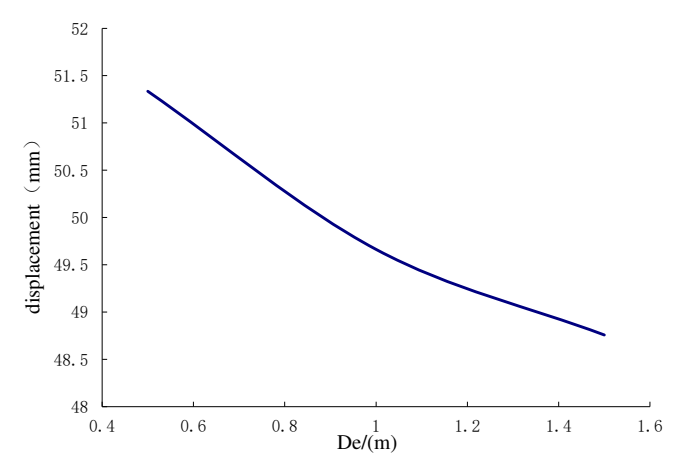

Fig. 15. The effect of equivalent width $D_{e}$ on the displacement of the anchor-pulling system.

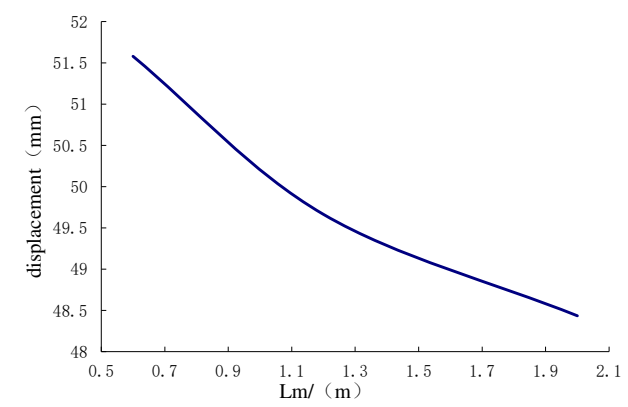

Fig. 16. The effect of equivalent length $L_{m}$ on the displacement of the anchor-pulling system

As illustrated in Figure 15 and Figure 16, the effects of the design parameters of the anchor piers on the displacement deformation of the anchor-pulling system are almost the same. As the size increases, the displacement deformation gradually decreases, and the front section decreases quickly, while the rear section becomes gradually smooth. Here, the equivalent width $D_{e}$ and length $L_{m}$ mainly affect the compression performance of the soil on the front of anchor piers $S_{3}$. The anchor piers can be seen as rigid bodies where horizontal displacement takes place. Increasing the size means increasing the contact area between the anchor pier and soil body. With this increase, the compression performance of the soil on the front of the anchor piers decreases. However, the effect of the height $H$ on the displacement deformation of the anchor-pulling system is the contribution to the relative shear displacement between the anchor piers and the surrounding soil $S_{2}$. When $H$ grows, $S_{2}$ grows accordingly. However, theoretically, the larger the effect of the size, the better it is. Because of the constraint of topographic conditions, construction conditions and economic benefits in practical engineering, it is necessary to choose the best size so that the anchor pier provides enough anchor force and saves all kinds of resources. The best design dimensions suggested are $D_{e}=1.2 \mathrm{~m} \sim 1.8 \mathrm{~m}, L_{m}=1.5 \mathrm{~m} \sim 2.5 \mathrm{~m}$, and $H=1.0 \mathrm{~m} \sim 1.6 \mathrm{~m}$.

\subsection{The numerical validation}

\subsubsection{The establishment of the finite element model}

When the finite element model of the anchor-pulling system and surrounding soil is created, the constitutive model of the surrounding soil uses the Mohr-Coulomb elastoplastic model. The anchor pier and surrounding soil use 
eight nodes as oparametric elements, such as solid45, of which the basic grid unit is cubic units. When the grid is divided, the grid between the anchor pier and the surrounding soil contact is dense. The LINK10 unit is used to simulate cables, which have a bilinear stiffness matrix, so that it can simulate not only tensile bar units but also compressed bar units. For example, when the pull-up option is used alone, if the unit is under pressure, its stiffness disappears so that it can be used to simulate the relaxation of cables or chains. This feature is very significant for the static problem of wire rope, which uses a unit to simulate the entire cable. It can also be used for dynamic analysis with inertial or damping effects when the needed relaxation unit should pay attention to its performance rather than its movement. The soil is homogeneous soil. The soil physical parameters and structure design parameters are consistent with the theoretical calculation parameters mentioned above. The tensile force of the cable is exerted on the nodes as a force. The top surface of the model is free, and the normal displacements of the remaining faces are constrained such that the displacements are zero. The contact of the anchor pier and surrounding soils is a rigidflexible surface-to-surface contact element to reflect the interaction. The surface of the anchor pier is regarded as the "target" surface, and the surface of the soil body is regarded as the "contact" surface. The coefficient of friction and normal penalty stiffness are 0.35 and 0.15 , respectively. The scope of interaction between the anchor pier and the surrounding soil in the model is taken as $15 \mathrm{~m} \times 11 \mathrm{~m} \times 12 \mathrm{~m}$, referring to past experience in engineering and the research data of the effect scope that the related anchors have had on the soil. The values of the model geometric parameters and physical and mechanical parameters are the same as in section 5.1. The finite element model is shown in figure 17.

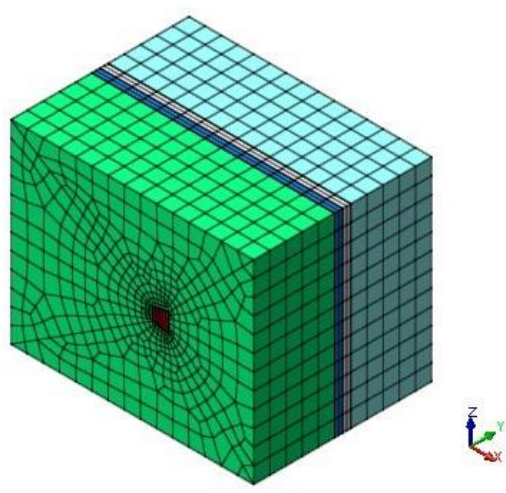

5.3.2 The calculation results

Fig. 17. Finite element model of the anchor-pulling system and surrounding soil.

Figure 18 and Figure 19 are the displacement nephograms of the soil around the anchor piers for $100 k N$ and $400 k N$, respectively. The soil displacement increases with increasing load, the affected area will increase and become uniform, and the area under load will also increase. The soil within the range of $1 \sim 3 \mathrm{~m}$ around the anchor pier is greatly affected, accounting for $80 \%$ of the total force. The soil around the anchor pier should be reinforced, 
and the anchoring force should be enhanced in the design.

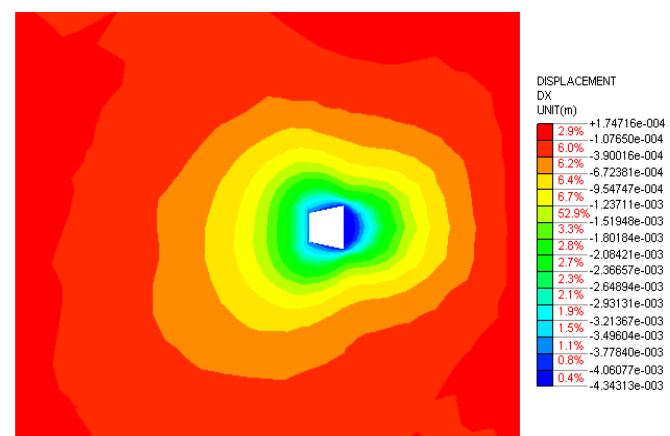

Fig. 18. Displacement fringe of soil around the anchor piers for $100 \mathrm{kN}$.

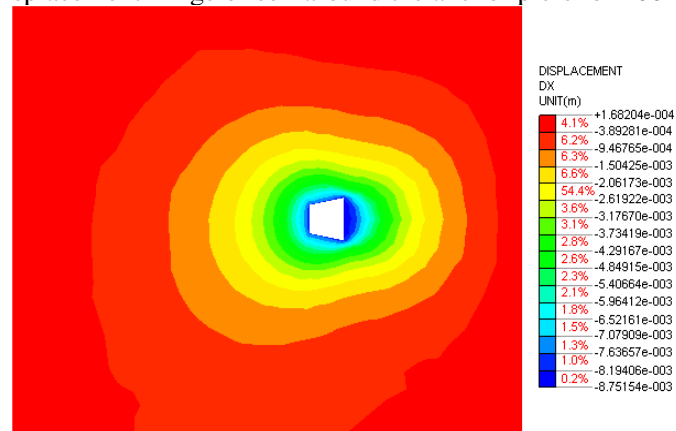

Fig. 19. Displacement fringe of soil around the anchor piers for $400 \mathrm{kN}$.

Figure 20 shows that the displacement of the soil around the anchor pier increases with increasing load, and the added value is obvious at approximately $2 \sim 3 \mathrm{~mm}$. Figure 21 shows that the increase in load has a great effect on the soil in front of the anchor pier. As the load increases, the compressive deformation of the soil gradually increases. As the distance from the anchor pier increases, the displacement of the soil decreases, and the scope of influence gradually decreases. The displacement of the soil tends to be stable beyond 4 5 $\mathrm{m}$ from the anchor pier.
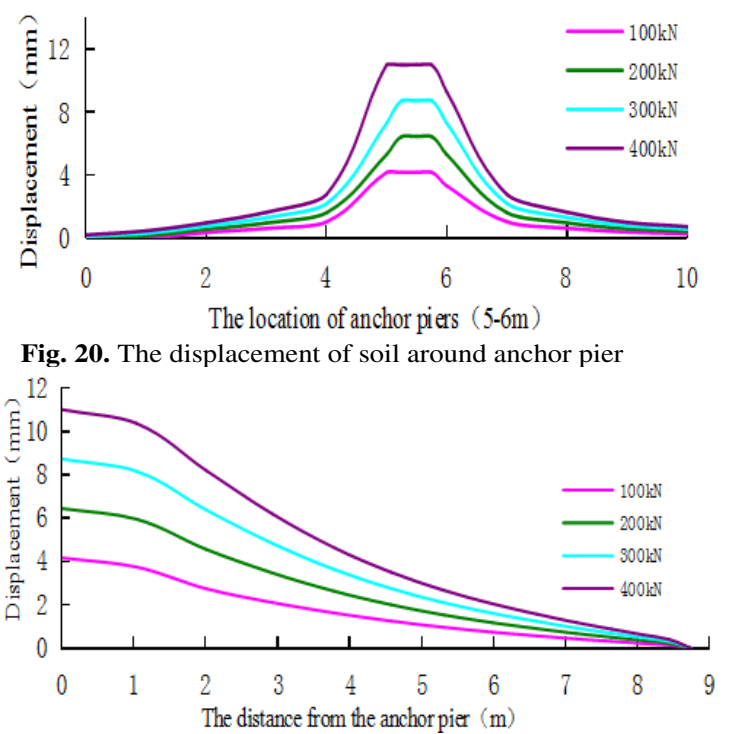

Fig. 21. The horizontal displacement of soil along cable axis

5.3.3 Comparison of theoretical calculation and numerical simulation results at the time of load variation

To verify the correctness of the theoretical calculation, we compare the theoretical calculation with numerical simulation results of displacement deformation of anchor-pulling system under different pulling force of stayed cable. 
The results are shown in Figure 22.

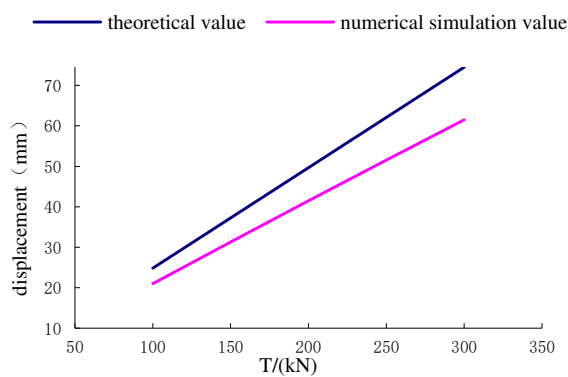

Fig. 22. Comparison of theoretical calculation and numerical simulation results

As seen from Figure 22, the theoretical and numerical simulation results are consistent, showing a linear growth trend. The slope difference of the two straight lines is approximately $5 \%$, which meets the accuracy requirements of geotechnical engineering. As the restraint effect of the surrounding soil on the anchor pier is not fully considered, the theoretical calculation result is too large. The deformation of anchor $S_{1}$ in displacement deformation is the same, and the relative shear displacement $S_{2}$ of the anchor pier and the soil and the compressive deformation $S_{3}$ of the soil at the front end of the anchor pier are 1.25 times and 1.08 times the numerical simulation results, respectively. The change in $S_{2}$ in the calculation results is large and should be taken into account in the design.

\section{Conclusion}

This paper provides a comprehensive analysis of the loading process and destruction mechanism of the anchorpulling system for a new debris flow grille dam, which was proposed by the author, establishes a calculation model of the anti-pulling force and displacement deformation in the anchor-pulling system, and systematically analyzes the influence of various parameters. The results can provide a theoretical reference for the promotion and application of the new debris flow grille dam.

(1) According to the destruction modes of the anchor-pulling system and the simplified calculation model, the formulas for calculating the anti-pulling force and the total displacement are given. The anti-pulling force $T_{b}$ is composed of two parts: the anti-pulling force $T_{1}$ provided by the frictional resistance of the sidewalls and the positive pressure $T_{2}$ on the front of the anchor piers. The total displacement of the system $S$ is composed of three parts: the elastic deformation $S_{1}$ of the stayed cable, relative shear displacement $S_{2}$ between anchor piers and the surrounding soil and the compression deformation $S_{3}$ of the soil on the front of anchor piers.

(2) As the elastic modulus of the soil around the anchor pier increases, the displacement deformation decreases gradually. When the elastic modulus is less than ${ }^{35 \mathrm{~N} / \mathrm{mm} 2}$, the curve is steep, and the deformation is obviously reduced. After more than ${ }^{35 \mathrm{~N} / \mathrm{mm} 2}$, the curve gradually becomes gentle, and the displacement deformation tends to be stable. The change in elastic modulus mainly affects the relative shear displacement $S_{2}$ of the anchor pier and soil and the 
compressive deformation $S_{3}$ of the soil at the front end of the anchor pier. Among these, $S_{2}$ accounted for $89 \%$, and $S_{3}$ accounted for $11 \%$. When the Poisson ratio increases, the displacement deformation also increases. Poisson's ratio has the greatest influence on the relative shear displacement $S_{2}$ of the anchor pier and soil, accounting for approximately $96.4 \%$. The design parameters should be selected correctly during design.

(3) As the size of the anchor piers increases, the displacement deformation decreases gradually. Here, the equivalent width $D_{e}$ and length $L_{m}$ mainly affect the compression deformation $S_{3}$ of the soil on the front of anchor piers. The height $H$ mainly affects the relative shear displacement $S_{2}$. When $H$ grows, $S_{2}$ grows either. The constraint of topographic conditions, construction conditions and economic benefits should be considered in practical engineering. The suggested economic design dimensions are $D_{e}=1.2 \mathrm{~m} \sim 1.8 \mathrm{~m}, L_{m}=1.5 \mathrm{~m} \sim 2.5 \mathrm{~m}$, and $H=1.0 \mathrm{~m} \sim 1.6 \mathrm{~m}$.

(4) Theoretical and numerical simulation results are consistent, showing a linear growth trend. The slope difference of the two straight lines is approximately 5\%, which meets the accuracy requirements of geotechnical engineering. In the theoretical calculation results for displacement deformation, the relative shear displacement $S_{2}$ of the anchor pier and the soil and the compressive deformation $S_{3}$ of the soil at the front end of the anchor pier are 1.25 times and 1.08 times the numerical simulation results, respectively. The change in $S_{2}$ in the calculation results is large and should be taken into account in the design.

\section{References}

1. XIA, H.B. \& WANG, W.J. Influence of the new type of multi - transverse bolt soil anchor and bolt spacing on the bearing capacity. Journal of Henan University of Urban Construction. 28(5), 99-101. https://doi.org/10.14140/j.cnki.hncjxb.2019.05.001(2019).

2. Zhang, L.W. \& Wang, R. Research on status quo of anchorage theory of rock and soil. Rock and Soil Mechanics. 23(5), 99-101. https://doi.org/ 10.16285/j.rsm.2002.05.024(2002).

3. Feng, Z.J., et al. Study on prestress long term loss of anchor cable considering coupled multiple factors. Rock and Soil Mechanics. 42(8), 2215-2224. https://doi.org/10.16285/j.rsm.2020.1506(2021).

4. HOLLENBECK, E., MARLOTH, R. \& ES-SAID, O.S. Case study-seams in anchor studs. Engineering Failure Analysis. 10(2), 209-213. https://doi.org/10.1016/S1350-6307(02)00050-X(2003).

5. SERRANO, A. \& OLALLA, C. Tensile resistance of rock anchors. International Journal of Rock Mechanics and Mining Sciences. 36(4), 449-474. https://doi.org/ 10.1016/S0148-9062(99)00021-2(1999).

6. Chen, G.Z. The study of some problems in the anchorage engineering for soil and rock. Dalian University of Technology(2007).

7. Liang, Y.Y. Study on anchoring mechanism of underreamed pressure ground anchor. China Academy of 
Railway Sciences(2012).

8. Huang, Z.Q., Bai, D.W., Zhang, Q. \& Cheng, Z. Simulation research of earth anchor penetration into the formation based on ANSYS/LS-DYNA. Journal of Yangtze University (Natural Science Edition). 12(17), 5861. https://doi.org/10.16772/j.cnki.1673-1409.2015.17.014 (2015).

9. Zhang, X.J., Li, B.L. \& Zhao, J.J. Study on seismic structure system of super long-span partially groundanchored cable-stayed bridges. JOURNAL OF ZHEJIANG UNIVERSTY OF TECHNOLOGY. 49(1), 3946(2021).

10. Han, Q.Y., Wang, Y.W., Gui, H.H. \& Zhu, G.M. The Application of Vertical Anchor Rod Anchor in Gobi Transmission Line Construction. JOURNAL OF ELECTRIC POWER. 29(5), 431-438. https://doi.org/10.13357/j.cnki.jep.002427(2014).

11. Pijush SAMUI, Dookie KIM \& Bhairevi G. AIYER. Pullout capacity of small ground anchor: a least square support vector machine approach. Journal of Zhejiang University-Science A (Applied Physics \& Engineering). 16(4), 295-301. https://doi.org/10.1631/jzus.A1200260(2015).

12. Wang, W.H. Application of anchor block underground diaphragm wall in water conservancy projects construction. South-to-North Water Transfers and Water Science \& Technology. 29 (5), $431-438$. https://doi.org/10.13476/j.cnki.nsbdqk.2008.01.080(2008).

13. Chen, X.Q., You, Y., Cui, P., Li, D.J. \& Yang, D.X. New control methods for large debris flows in Wenchuan earthquake area. Journal of Sichuan University (Engineering Science Edition). 45(1), 14-22. https:// doi.org/10.15961/j.jsuese.2013.01.004(2013).

14. Shi, S.W., LIU, J.K., CAI, Q. \& ZHOU, L.X. Research of Small Caliber Steel Pipe Piles to Reinforce the Foundation of Check Dam and Preventit from Scouring by Debris Flow. ADVANCED ENGINEERING SCIENCES. 51(5), 586-593. https://doi.org/ 10.15961/j.jsuese.201800860(2019).

15. Wang, Y.S., Zhu, Y.P. \& Jin PH. Modeling and analysis of the coupling wear random process of debris flow drainage structure. Journal of Jilin University (Earth Science Edition). 43(5), 1556-1562. https://doi.org/10.13278/j.cnki.jjuese. 2013.05.025(2013).

16. Chen, N.S., Zhou, H.B., Lu, Y., Yang, L. \& Lv, L.Q. Analysis of benefits of debris flow control projects in southwest mountain areas of China. JOURNAL OF CHEN DOU UNIVERSITY OF TECHNOLOGY(Science \& Technology Edition). 40(1), 50-58. https://doi.org/ 10.3969/j.issn.1671- 9727. 2013. 01.008(2013).

17. Tang, X.C., et al. A study on the ecologic benefit evaluation model of valley debris flow controlling. The Chinese Journal of Geological Hazard and Control. 11(2), 86-87. https://doi.org/10.16031/j.cnki.issn.10038035. 2000. 02.020(2000).

18. Tang, X.C., Yu, C.Q. \& Li, H.R. Analysis of ecologic benefit of valley debris flow control from stability of ecologic system. The Chinese Journal of Geological Hazard and Control. 11(2), 57-62. https://doi.org/10.16031/j.cnki.issn.1003-8035. 1996. 02.009(1996). 
19. Lo, S.Z. \& Xu, Z.M. Basin morphology characteristics of the giant debris flow in the Dongyuege gully near the Nujiang River. HYDROGEOLOGY \& ENGINEE R ING GEOLOGY. 43(6), 1-11. https://doi.org/10.16030/j.cnki.issn.1000-3665.2016.06.22(2016).

20. Kana NAKATANI, Yuki OKUYAMA, Yuji HASEGAWA, Yoshifumi SATOFUKA \& Takahisa MIZUYAMA, 2013. Influence of housing and urban development on debris flow flooding and deposition. Journal of Mountain Science. 10(2), 273-280. https://doi.org/ 10.1007/s11629-013-2507-x(2013).

21. Wang, Y.S., Zhu, Y.P. \& Wang Y.N. Seismic response analysis of a new ground anchor counter fort grille-dam for debris flow under near-fault pulse-like ground motions. SHUILI XUEBAO42(supp2), $162-167$. https://doi.org/10.13243/j.cnki.slxb.2012.s2.015(2012).

22. Zhu, Y.P. \& Xu, J. Analysis of Two-Way Fluid-Solid Coupling of Debris Flow Blocking Dam. Journal of Gansu Sciences. 27(1), 100-104. https://doi.org/10.16468/j.cnki.issn/1004-0366.2015.01.022(2015).

23. MOHURD. Technical code for building slop engineering (GB 50330-2013), China Building Industry Press, Beijing, China. p43(2014).

24. Mi, H.Z. Elastic Mechanics. Tsinghua University press, Beijing, China. P2(2013).

25. Chen, X.Z., 2004. Soil Mechanics and Geotechnical Engineering(Fourth Edition), Tsinghua University Press, Beijing, China.p80(2004).

\section{Acknowledgments}

Financial support from the National Natural Science Foundation of China (Grant No. 51768039) is highly appreciated. Financial support from the Industrial Support Program of Higher Education of Gansu Province (2020C-40) and Hongliu Support Funds for Excellent Youth Talents of Lanzhou University of Technology (Grant No. 04-062002) is also highly appreciated.

\section{Author contributions statement}

Y.S., W: Methodology, Formal analysis. B.H., L: Data Curation, Writing - Original Draft. J.S., L: Writing - Review \& Editing. X.B., Z: Data Verification. All authors reviewed the manuscript.

\section{Additional information}

The authors declare that they have no conflicts of interest regarding the publication of this paper. 